DOI: 10.20472/IAC.2018.038.017

YOUNG-HAN KIM

Sungkyunkwan University, Korea, Republic of

\title{
WELFARE IMPLICATIONS OF UPSTREAM SUBSIDY, COUNTERVAILING DUTIES, AND LIMITED VERIFIABILITY
}

\begin{abstract}
:
Based on a simple model integrating political contribution provided by exporting firms and verifiability problem of export subsidy for the upstream firms within intricately fragmented production processes, this paper demonstrates that strategic export policies influenced by political contribution can deteriorate social welfare. Moreover, when it is more difficult to identify the government subsidy provided to upstream firms within complicated vertical value chains, there is larger distortion due to higher export subsidies manipulated by the political contribution. Therefore, even if countervailing duties are imposed against the export subsidies, when the probability to detect the export subsidy is lower, the export subsidy dominates the countervailing duty with the distortion due to political contribution aggravated by the lower detection probability. These results implicate that with the deepening fragmentation of global production networks, as it gets more difficult to verify the subsidy provided to upstream production processes, it is more likely that the indirect and hidden strategic government interventions can be made. Therefore, it is imperative to make further efforts to enhance the verifiability of the hidden subsidies to reduce welfare deterioration caused by the politically manipulated strategic trade policies.
\end{abstract}

\section{Keywords:}

Strategic trade intervention, Political contribution, Verifiability of hidden subsidy, beggaring thyself, beggaring thy neighbor

JEL Classification: F12, F13, L13 


\section{Introduction}

With the unprecedented progress of global market integration in recent decades, the intensifying cross-border competition within oligopolized industries has made the government intervention to provide strategic edge for domestic firms a prevalent feature. At the same time, fragmentation of global production networks has become a dominant corporate strategy with the advent of information technology revolution and sharp reduction in cross-border transaction costs. As a result, it has become much more difficult and complicated to identify government intervention to provide competitive edge to a certain stage of production process within the whole fragmented production processes.

OECD (2010) has reported that EU government intervention to provide competitive edge to domestic firms has increased steadily to the level of $1 \%$ of total EU GDP even if EU has applied the strictest control over the subsidy among OECD countries. Moreover, OECD reports that "it is getting more difficult to identify the intervention since a wide variety of different instruments are used including direct subsidies, tax breaks or loan guarantees in various stages of production processes. Governments subsidize inputs or buy a firm's products at an above-market price." 1 OECD is also concerned about various types of distortion caused by government subsidies targeting to provide strategic advantages to their domestic firms. The costly distortions caused by government subsidies take the form of price distortion, productive inefficiency caused by capital misallocation, and the social cost of rent-seeking via politically manipulated subsidies. Moreover, in 2015, U.S. administration released a special report to U.S. congress that identifies Chinese government's stealth subsidies to make their products unfairly competitive in the US market. The U.S. national effort to monitor and identify types of unfair subsidies will be significantly strengthened under the Trump administration. ${ }^{3}$

Reflecting these trends, this paper aims to examine welfare implication of government subsidies to provide strategic advantage for domestic firms focusing on the case where the subsidy is offered to an upstream firm within vertical production networks. In addition, we determine the welfare impacts of varying level of verifiability of the subsidy given to the upstream firm within complicated vertical production processes.

The seminal papers by Brander and Spencer (1985) and Eaton and Grossman (1986) have shown that strategic trade policies can improve social welfare by providing strategic advantage, i.e., the Stackelberg leadership advantage, to domestic firms as long as the competing government does not take equivalent or countervailing policy

\footnotetext{
1 See OECD (2010), Policy Roundtables: Competition, State Aids and Subsidies

3 Mr. Trump's trade policy on China will be tough and aggressive, having publicly mentioned that "China's unfair subsidy behavior is prohibited by the terms of its entrance to the WTO and I intend to enforce those rules and regulations. And basically, I intend to enforce the agreements from all countries, including China."
} 
measures. Nonetheless, strategic trade policies turned out to deteriorate social welfare when the policies are manipulated with political contribution even if the competing government takes no action. (Kagitani, 2009). The politically manipulated strategic trade policies deteriorate social welfare because the distortion caused by the rent seeking incentives of political contribution dominates strategic gains from strategic trade policy intervention. Although welfare deteriorating effect of politically manipulated strategic trade policies was well demonstrated by earlier literatures such as Kagitani (2009) and Fung et. Al (2009), the impacts of increasingly complicated vertical production networks and the resulted difficulties in identifying the subsidies given to an upstream production process within the long range of vertical production processes have not been properly analyzed as far as we understand. This paper targets to examine how complicated vertical production networks and the limited verifiability of subsidies to upstream firms influences the welfare effects of strategic trade policies.

Bagwell and Staiger (2006) analyze the economic impacts of the international subsidy discipline by formulating the GATT/ WTO subsidy game: with a countervailing duty, an importing country can challenge any positive subsidy offered by an exporting country. In the game, they show that GATT subsidy rule is more efficient than WTO subsidy rule. The study is along the line with the researches that argue against the current WTO subsidy disciplines (Sykes, 2005; Brou and Ruta, 2013; Horlick and Peggy, 2016; Lee, 2016). In our study, we also doubt about the efficiency of the WTO dispute system. Our main result shows that the exporting country has always an incentive to offer the upstream subsidy that never be offset by the countervailing duty imposed by the importing country.

This paper is also related to a strand of literature regarding the economic impact of countervailing duties on social welfare (Grossman, 1986; Dixit, 1988; Collie, 1991). Spencer (1988) examines the condition under which the countervailing duty offsets the capital subsidy. In a similar context, Ishikawa and Komoriya (2007) studies the effect of capital subsidy and export subsidy, and the countervailing duty when there are cost asymmetries between subsidized firms. Brou and Ruta (2013) study how the optimal design of the subsidy rule under GATTMTO affects domestic subsidies within trade agreements.

We set up a simple oligopoly model where representative firms from two countries compete a la Cournot fashion based on intermediate goods provided by upstream firms of each country. The domestic government considers the strategic trade policies while she is politically biased by the political contribution made by the domestic firm that can influence the policies. Therefore, corporate sectors' political contribution schedule can actually influence and design the government policies since the policy maker's appreciation level of the political contribution is known to corporate sectors. Moreover, we consider the limited verifiability of the subsidy provided to the upstream firms within complicated vertical production networks. Based on the model, this paper 
demonstrates that strategic export policies influenced by political contribution can deteriorate social welfare. Moreover, when it is more difficult to identify the government subsidy provided to upstream firms within complicated vertical value chains, there is larger distortion due to higher export subsidies manipulated by the political contribution. Therefore, even if countervailing duties are imposed against the export subsidies, when the probability to detect the export subsidy is lower, the export subsidy dominates the countervailing duty with the distortion due to political contribution aggravated by the lower detection probability. These results implicate that with the deepening fragmentation of global production networks, as it gets more difficult to verify the subsidy given to upstream production processes, it is more likely that the indirect and hidden strategic government interventions can be made. Therefore, it is imperative to make further efforts to enhance the verifiability of the hidden subsidies to reduce welfare deterioration caused by the politically manipulated strategic trade policies.

This paper is structured in the following way. Section 2 discusses the benchmarking model and the feature of equilibrium without political contribution in the exporting country. Section 3 examines the equilibrium where political contribution is made by the exporting firms to influence the government policies. Section 4 determine the welfare impacts of political contribution in the strategic trade policies with varying verifiability of the subsidy provided to the upstream firms. Section 5 discusses the policy implications and concludes.

\section{Benchmarking discussions: Equilibrium without political contribution in the exporting country}

There are two countries, an exporting country and an importing country. In the exporting country, there are an upstream firm (firm $u$ ) and a downstream firm (firm 1) that produces a good and exports it to the importing country. In the importing country, there is a local firm (firm 2) that serves its own country. In the importing country, firm 1 and firm 2 compete a la Cournot fashion. A representative consumer in the importing country has a quasi-linear preference. Good $b$ is a numeraire and is a perfectly competitive good. The utility function of the consumer is given as follows:

$$
U\left(q_{1}, q_{2}, b\right)=a q_{1}+a q_{2}-\frac{1}{2} q_{1}^{2}-\frac{1}{2} q_{2}^{2}-q_{1} q_{2}+b, \quad a>0,
$$

where $q_{1}$ and $q_{2}$ are the consumption of good 1 and 2, respectively. From the utility maximization, we obtain the following inverse demand functions for good 1 and 2 as $p_{i}=a-q_{i}-q_{j}$ for $i, j=1,2$ and $i \neq j$.

The profit of the downstream firm $\pi_{1}$, the profit of the upstream firm $\pi_{u}$, and the profit of the foreign firm $\pi_{2}$ are, respectively, 
$\pi_{1}=\left(p_{1}-I\right) q_{1}=\left(a-q_{1}-q_{2}-I\right) q_{1}$,

(2)

$\pi_{2}=\left(p_{2}-c\right) q_{2}=\left(a-q_{2}-q_{1}-c\right) q_{2}$,

(3)

$\pi_{u}=\left(I-c_{I}+s\right) q_{1}=(I-\mathrm{c}+s) q_{1}$

where $I$ is the price of the intermediate good, $c_{I}$ is the unit cost of producing the intermediate good that is equal to $c$, and $c$ is the production cost of firm 2. To produce one unit of the final good, one unit of the intermediate good is required (Lin and Saggi, 2007). It is assumed that firm $u$ in the exporting country does not provide the intermediate good to firm 2 in the importing country. Firm 2 purchases the intermediate good at a cost of $c$ from the local market. Moreover, the government of the exporting country provides production subsidy to the upstream firm by $s$.

We assume that there is a probability of verification $\mu \in[0,1]$ (Bull and Watson, 2004; Kvaløy and Olsen, 2009). The importing country can request WTO panel in challenging the exporting country's subsidy practice. WTO panel verifies the case with the probability $\mu$, and then the countervailing duties will be enforced; the importing country will impose a countervailing duty against the subsidized good made in the exporting country. With probability $1-\mu$, however, the importing country will not impose any countervailing duty due to the failure to verify the case.

The model is structured as a four-stage game. In stage 1, the exporting government sets its production subsidy. In stage 2, taking the production subsidy as given, firm $u$ chooses a profit-maximizing price for the intermediate goods provided to firm 1 . In stage 3 , the importing country's government challenges the legitimacy of the production subsidy according to WTO Subsidy Countervailing Measure (SCM) agreement. In stage 4, if the subsidy provided to the upstream firm is verified, the foreign country is allowed to impose a countervailing duty on the imports. Then firm 1 and firm 2 compete a la Cournot fashion. The solution concept of the game follows subgame-perfect Nash equilibrium. Using backward induction, we solve the game.

\section{2-1. Upstream Subsidy, Countervailing Duties, and Verifiability}

When production subsidy for the upstream firm is unverifiable, in the fourth stage of the game, firm 1 and firm 2 maximize profits by choosing their quantity after observing the intermediate good price. Solving for the Cournot-Nash equilibrium quantities, we obtain the equilibrium quantities, $q_{1 N}$ and $q_{2 N}$, and the equilibrium profits, $\pi_{1 N}$ and $\pi_{2 N}$ as: 


$$
\begin{gathered}
q_{1 N}(I)=(a+c-2 I) / 3, \\
q_{2 N}(I)=(a-2 c+I) / 3, \\
\quad=(a-2 c+I)^{2} / 9
\end{gathered}
$$

$$
\pi_{1 N}(I)=(a+c-2 I)^{2} / 9, \quad \pi_{2 N}(I)
$$

In the non-verifiable case where the WTO panel fails to prove the subsidy program of the exporting country, firm 1 obtains $\pi_{1 N}$ while firm 2 has $\pi_{2 N}$. The quantities and the profits of the two firms, in the equilibrium, are described as a function of the price of the intermediate good $I$ that will depend on the level of upstream subsidy $s$.

However, if the exporting country's subsidy is verified by the WTO panel, the importing country will impose a countervailing duty $f$ on the imported goods. The importing country chooses the countervailing duty that maximizes the country's welfare within the range allowed by the WTO rules and firm 1 chooses the optimal quantity that maximizes its profits net of $f$ as 4 :

$$
\begin{gathered}
f=\operatorname{argmax} S W_{2} \\
\text { where } S W_{2}=U\left(q_{1 V}(I, f), q_{2 V}(I, f), b\right)+\pi_{2 V}(I, f)+ \\
f q_{1 V}(I, f) \\
q_{1}=\operatorname{argmax} \pi_{1}(I, f)=\left(p_{1}-I-f\right) q_{1}=\left(a-q_{1}-q_{2}-I-f\right) q_{1} .
\end{gathered}
$$

After observing both the intermediate good price and a countervailing duty, firm 1 and firm 2 choose a profit-maximizing quantity. We obtain the equilibrium quantities, $q_{1 V}$ and $q_{2 V}$, and the equilibrium profits, $\pi_{1 V}$ and $\pi_{2 V}$, of the four-stage subgame as

$$
q_{1 V}(I, f)=(a+c-2 f-2 I) / 3, \quad q_{2 V}(I, f)=(a-2 c+f+I) /
$$

\footnotetext{
4 "Material Injury" is a key concept when the importing country/WTO sets a countervailing duties. According to Antidumping and countervailing duty handbook (2015) released by U.S. International Trade Commission, material injury includes not only "(1) the volume of imports of the subject merchandise, (2) the effect of imports of that merchandise on prices in the United States for domestic like products, and (3) the impact of imports of such merchandise on domestic producers of domestic like products in the context of production operations within the United States. but also (4) actual and potential declines in output, sales, market share, profits, productivity, return on investments, and utilization of capacity; (5) factors affecting domestic prices; (6) actual and potential negative effects on cash flow, inventories, employment, wages, growth, ability to raise capital, and investment; (7) actual and potential negative effects on the existing development and production efforts of the domestic industry, including efforts to develop a derivative or more advanced version of the domestic like product." Thus, de facto, we conclude that the importing country sets a countervailing duties to maximize the social welfare.
} 


$$
\pi_{1 V}(I, f)=(a+c-2 f-2 I)^{2} / 9, \quad \pi_{2 V}(I, f)=(a-2 c+f+I)^{2} / 9
$$

Substituting (9) and (10) into (7) and taking the derivative the (7) with respect to $f$ gives the optimal countervailing duty as:

$$
f^{*}=(2 a-c-4 I) / 11
$$

The optimal countervailing duty is more sensitive to a price of the intermediate good relative to a market size and a production cost. Countervailing duties increase with the intermediate good price. It implies that the importing country government sets a higher countervailing duties when observing a lower intermediate good price.

Next, consider the third stage of the game in which the importing country challenges the validity of the exporting country's production subsidy under the WTO SCM agreement. With the probability $\mu$, the WTO panel verifies the exporting country's practice of the production subsidy, in which case the foreign government will be authorized to retaliate by choosing a countervailing duty on the imports. With the probability $1-\mu$, the panel fails to prove the use of the subsidy, in that case the importing country will not impose the countervailing duty.

In stage 2, firm $u$ sets a profit-maximizing price for the intermediate good, taking into account the demand for the intermediate good that is derived from the expected demand of the final good $E\left[q_{1}(I, \mu)\right]$. Based on the derived demand, firm $u$ seeks to maximize its expected profits with respect to the intermediate price (Goh, 2005; Lin and Saggi, 2007):

$$
I=\operatorname{argmax} E\left[\pi_{u}\right]=(I-\mathrm{c}+s) E\left[q_{1}(I, \mu)\right]
$$

where $E\left[q_{1}(I, \mu)\right]=(1-\mu) * q_{1 N}(I)+\mu * q_{1 V}(I)$ and let $E\left[q_{1}(I, \mu)\right]$ define the expected demand of intermediate goods.

Taking the first derivative of the demand curve with respect to the probability, we obtain $\partial E\left[q_{1}(I, \mu)\right] / \partial \mu<0$ since $q_{1 N}(I)>q_{1 V}(I)$. From the maximization problem, we obtain the optimal intermediate price and the optimal profits as:

$$
\begin{aligned}
I(\mu)= & \frac{a}{4}+\frac{3 c(11-2 \mu)}{4(11-4 \mu)} \\
& -\frac{s(\mu)}{2}
\end{aligned}
$$




$$
\begin{gathered}
E\left[\pi_{u}\right] \\
=(I(\mu)-\mathrm{c}+s) E\left[q_{1}(I(\mu), \mu)\right]
\end{gathered}
$$

The impact of the subsidy $s$ on the intermediate good price is given as $\partial I(\mu) / \partial s<$ 0 . Using the envelope theorem, we simply derive the effect on the upstream firm's profits of the production subsidy as $\partial \mathrm{E}\left[\pi_{u}\right] / \partial s=E\left[q_{1}(I(\mu), \mu)\right]>0$. The envelope theorem also shows the effect of the probability of the verification on the upstream firm's profit as $\partial \mathrm{E}\left[\pi_{u}\right] / \partial \mu=-(I(\mu)-\mathrm{c}+s)\left[q_{1 N}(I(\mu))-q_{1 V}(I(\mu))\right]<0$. We summarize the result into the following Lemma.

Lemma 1. The upstream production subsidy decreases the intermediate price while increasing the upstream firm's profits. The probability of the verification decreases the upstream firm's profits.

From Lemma 1, first, we focus on the effect of the upstream subsidy on the intermediate good price and the upstream firm's profits. Note that the upstream subsidy drops the optimal price of the intermediate good. If the government offers $s$ to firm $u$, half of total $\mathrm{s}$ (or $50 \%$ of $s$ ) will be passed through to firm 1 producing the final good in the duopoly market. We call it a pass-through effect (Gaudin, 2016). By virtues of the upstream subsidy, the upstream firm provides the intermediate good to firm 1 at a reduced price, which induces firm 1 to improve its export performance, thereby increasing a demand for the intermediate good. As a result, firm $u$ can achieve higher profits. Second, the probability of the verification reduces the upstream firm's profits. When the probability becomes large, firm 1 produces less, so that the expected demand for intermediate good decreases, leading to a reduction in profits of the upstream firm.

The exporting country's government is concerned with maximizing social welfare. Let $E[W(s)]$ represent the social welfare of home country. In stage 1 , the home government chooses the optimal level of the subsidy, $s$, to maximize the aggregate welfare:

$$
s=\operatorname{argmax} E[W(s)]
$$

where $E[W(s)]=(1-\mu) * E\left[\pi_{1 N}(\mu)\right]+\mu * E\left[\pi_{1 V}(I, f)\right]+E\left[\pi_{u}\right]-s E\left[q_{1}(I, \mu)\right]$.

From the welfare maximization problem, the equilibrium subsidy is obtained as:

$$
=\frac{\begin{array}{c}
s_{c}^{*}(\mu) \\
a\left(1331-1276 \mu+288 \mu^{2}\right)-c\left(1331-1474 \mu+192 \mu^{2}\right)
\end{array}}{(11-4 \mu)(121+12 \mu)}
$$


The exporting country sets a positive production subsidy for the upstream firm that is passed through to the downstream firm. The optimal amount of the production subsidy is obtained as the subgame-perfect outcome of the four-stage game. Next, substituting the optimal subsidy into (12) and (13) gives the optimal price of the intermediate good and profits of the upstream firm. We obtain the optimal countervailing duty by substituting the optimal price of intermediate good into (11). Last of all, substituting the optimal price of intermediate good and the countervailing duty into (5),(6),(9), and (10) gives the equilibrium quantities and profits (see Table 1).

Proposition 1. As the probability of the verification decreases, (a) the government in the exporting country provides a higher level of subsidy, (b) the upstream firm sets a lower price of the intermediate good, and (c) the government of the importing country imposes a higher level of a countervailing duty. (d) the social welfare of the exporting country increases while the social welfare of the importing country decreases.

The proof is in Appendix A. Proposition 1 shows that when the probability of verifying the illegal subsidy decreases, the exporting country increases the production subsidy, which reduces a price of the intermediate good. In response to this, the importing country prepares a strong countervailing measure to protect its local firm from competing with the exporting firm that is indirectly subsidized through the intermediate good price. The result implies that a lower probability may result in a greater market distortion. At a lower probability, the exporting country distorts the market by offering a higher subsidy to which the importing country intervene the market by choosing a higher countervailing duty. The higher subsidy makes the exporting country better off while the higher countervailing duty makes the importing country worse off. We can calculate the size of the maximum distortion in each country by subtracting a social welfare level at the highest probability $(\mu=1)$ from the one at the lowest probability $(\mu=0)$. The maximum size of the welfare distortion in each country is as follows:

$$
\begin{aligned}
& S W_{1}(\mu=0)-S W_{1}(\mu=1)=\frac{3}{266}\left(7 a^{2}-21 a c+11 c^{2}\right) \\
& S W_{2}(\mu=0)-S W_{2}(\mu=1)=-\frac{3\left(50 a^{2}-131 a c+84 c^{2}\right)}{2888}
\end{aligned}
$$

The exporting country that distorts the market of the importing country by subsidizing the upstream firm improves its own social welfare while the importing country that is distorted by the subsidy experiences the welfare deterioration.

\section{Equilibrium with political contribution in the exporting country}

Consider a political market in which a production subsidy for the intermediate good is set by the strategic interaction between firm 1 and the exporting country's government. Firm 1 may exert influences on a political process through a political contribution. In exchange of the contribution, the firm obtains a production subsidy in the indirect way; 
the upstream firm receives the production subsidy passed through to the downstream firm. The incumbent policy maker tries to keep the political power by maintaining reputation and popularity through a campaign spending funded by the political contribution.

Accordingly, the exporting country's government concerns itself with the political donations received from the home downstream firm as well as the level of aggregate welfare. The government objective function consists of the aggregate welfare $W(s)$ and the political contribution $C_{p}$ by firm 1, i.e., politically weighted social welfare function. Accordingly, the government's objective function will take a similar form as in Grossman and Helpman (1994):

$$
\mathrm{G}(\mathrm{s})=\mathrm{W}(\mathrm{s})+(\theta-1) C_{p}
$$

where $\theta$ is the weight that the home country's government places on the political contribution. There is no restriction on the political contribution. If $\theta>1$, the government will pay more attention to the contribution with a heavier weight on political contribution than general voter's welfare $^{5}$.

The model is structured as a five-stage game. The timing of the game is as follows. In stage 1 , firm 1 offers the exporting country's government a campaign contribution schedule as a function of the subsidy provided by the government. In stage 2, the government sets its production subsidy, taking the contribution schedule as given. In stage 3 , taking the production subsidy as given, firm $u$ chooses a profit-maximizing price for the intermediate good provided to firm 1. In stage 4, the importing country's government challenges the legitimacy of the production subsidy under WTO SCM agreement. The WTO panel can prove the exporting country's practice of the production subsidy with the probability $\mu$, in which case the foreign government will be authorized to retaliate by choosing countervailing duties on the imports. With the probability $1-\mu$, the panel cannot prove the use of the production subsidy, in which case the foreign country will not impose countervailing duties on the imports. In stage 5 , if the upstream subsidy is verified (not verified), the importing country sets an optimal countervailing duty (zero duty) on the subsidized good, and firm 1 and firm 2 compete a la Cournot fashion. ${ }^{6}$ The solution concept of the game follows subgameperfect Nash equilibrium.

\footnotetext{
5 Kayalica Lahiri (2007) assume that $\theta>1$ so that the government puts a heavier value on the contribution when it receives more than when firm 1 pays to lobbyists.

6 The WTO rule on the Subsidy Countervailing Measure (SCM) goes as follows: 'Importing countries might be allowed to take countervailing measures such as duties against specific subsidies provided by the exporting country to export-related industries when such subsidies have caused significant damages to the importing country's industries.'
} 


\section{3-1. Upstream Subsidy, Countervailing Duties, and Verifiability with Political Contribution}

In the fifth stage of the game, in case of non-verifiable production subsidy for the upstream firm, after observing the intermediate good price, firm 1 and firm 2 maximize profits by choosing their quantities. Solving for the Cournot-Nash equilibrium quantities, we obtain the equilibrium quantities, $q_{1 N}$ and $q_{2 N}$, and profits, $\pi_{1 N}$ and $\pi_{2 N}$

$$
\begin{aligned}
q_{1 N}(I) & =(a+c-2 I) / 3, \\
& q_{2 N}(I)=(a-2 c+I) / 3, \\
\pi_{1 N}(I) & =(a+c-2 I)^{2} / 9, \quad \pi_{2 N}(I) \\
& =\frac{1}{9}(a-2 c+I)^{2} / 9
\end{aligned}
$$

In the fifth stage of the game, however, if the WTO panel verifies the upstream subsidy, the importing country sets the optimal countervailing duty $f$ on the imported good. The importing country's government sets an optimal countervailing duty that maximizes the country's welfare and firm 1 maximizes the profit as:

$$
\begin{array}{r}
f^{*}=\operatorname{argmax} U\left(q_{1 V}(I, f), q_{2 V}(I, f), \mathrm{b}\right)+\pi_{2 V}(I, f)+ \\
f q_{1 V}(I, f) \\
\pi_{1}(I, f)=\left(p_{1}-I-f\right) q_{1}=\left(a-q_{1}-q_{2}-I-f\right) q_{1} .
\end{array}
$$

After observing both the intermediate good price and the countervailing duty, firm 1 and firm 2 choose a profit-maximizing quantity. The equilibrium quantities, $q_{1 V}$ and $q_{2 V}$, and the equilibrium profits, $\pi_{1 V}$ and $\pi_{2 V}$, of the five-stage subgame in the verifiable case are

$$
\begin{aligned}
& q_{1 V}(I, f)=(a+c-2 f-2 I) / 3, \quad q_{2 V}(I, f) \\
& =(a-2 c+f+I) / 3 \\
& \pi_{1 V}(I, f)=(a+c-2 f-2 I)^{2} / 3, \quad \pi_{2 V}(I, f) \\
& =(a-2 c+f+I)^{2} / 9
\end{aligned}
$$

Substituting (19) and (20) into (7) and taking the derivative it with respect to $f$ gives the optimal countervailing duty as:

$f^{*}(I)=(2 a-c-4 I) / 11$. 
Next, consider the fourth stage of the game in which the importing country requests WTO panel to determine whether the exporting country uses an illegal subsidy. The WTO panel can prove it with the probability $\mu$, in which case the importing country imposes a countervailing duty on the subsidized good. Otherwise, a countervailing duty will not be enforced.

In stage 3 , firm $u$ chooses a profit-maximizing price for the intermediate good, taking into account the derived demand for the intermediate good, $E\left[q_{1}(I, \mu)\right]=(1-\mu) *$ $q_{1 N}(I)+\mu * q_{1 V}(I)$

$$
I^{*}=\operatorname{argmax} E\left[\pi_{u}\right]=(I-\mathrm{c}+s) E\left[q_{1}(I, \mu)\right]
$$

The home country's government is interested in collecting political contribution $C_{p}$. As well, the government is concerned with maximizing a social welfare. The political objective function of the home country's government consists of the political contribution and the social welfare. Let $E[W(s)]$ represent the aggregate welfare of the country. Let $E[W(s)]-C_{p}(s)$ represent the net social welfare of the country. In stage 2, the incumbent government chooses the optimal level of the subsidy to maximize its objective function, taking the political contribution schedule as given,

$$
s_{P}^{*}=\operatorname{argmax} E[W(s)]+(\theta-1) C_{p}(s)
$$

where $E[W(s)]=(1-\mu) * E\left[\pi_{1 N}(s, \mu)\right]+\mu * E\left[\pi_{1 V}(s, \mu)\right]+E\left[\pi_{u}(s, \mu)\right]-s E\left[q_{1}(s, \mu)\right]$. Note that when $\theta=1$, the government becomes a benevolent social welfare maximizer that sets an optimal production subsidy for the domestic firms since the political contribution is cancelled out in the political objective function due to the negative contribution in the firm's profit function.

The politically optimal subsidy satisfies the following condition:

$$
\begin{gathered}
\frac{d E[W(s)]}{d s}+(\theta-1) \frac{d C_{p}(s)}{d s} \\
=0
\end{gathered}
$$

Next, consider the first stage of the game in which firm 1 makes a political contribution contingent on the government's subsidy policy ${ }^{7}$. The profits net of the political

7 For a positive contribution, we apply truthful contribution schedules as in Grossman and Helpman (1994) and sets the schedule $C_{p}(s)=\max \left\{\mathrm{E}\left[\pi_{1}(s)\right]-\mathrm{B}_{1}\right\}$ where $\mathrm{B}_{1} \geq 0$ is reservation profits and is a positive constant. If we substitute it into (23), the objective function is transformed into. $s_{P}^{*}=\operatorname{argmax} E[W(s)]+(\theta-1) \mathrm{E}\left[\pi_{1}(s)-\mathrm{B}_{1}\right]$; the government chooses the optimal subsidy to maximize the joint welfare of the general voters and the firm. 
contribution is defined as $\mathrm{E}\left[\pi_{1}(s)\right]-C_{p}(s)$. The contribution schedule should satisfy the participation constraint of the government in which the politically weighted social welfare should not be lower than the social welfare without lobbying activity.

$$
\mathrm{E}[\mathrm{W}(\mathrm{s})]+(\theta-1) C_{p} \geq \mathrm{E}\left[\mathrm{W}\left(s_{c}^{*}\right)\right] .
$$

Firm 1 attempts to minimize the political contribution so that the participation constraint will be binding and we have

$$
C_{p}=\mathrm{E}\left[\mathrm{W}\left(s_{c}^{*}\right)\right]-\mathrm{E}[\mathrm{W}(\mathrm{s})] /(\theta-1) .
$$

Substituting it into $\mathrm{E}\left[\pi_{1}(s)\right]-C_{p}(s)$ yields $\mathrm{E}\left[\pi_{1}(s)\right]-\left(\mathrm{E}\left[\mathrm{W}\left(s_{c}^{*}\right)\right]-\mathrm{E}[\mathrm{W}(\mathrm{s})]\right) /(\theta-1)$. In the equilibrium, the optimal subsidy must satisfy

$$
\begin{gathered}
\frac{d \mathrm{E}\left[\pi_{1}(s)\right]}{d s}+\frac{1}{\theta-1} \frac{d \mathrm{E}[\mathrm{W}(\mathrm{s})]}{d s} \\
=0
\end{gathered}
$$

From the above equations, we derive the following equilibrium condition $d \mathrm{E}\left[\pi_{1}(s)\right] /$ $d s=d C_{p}(s) / d s$ implying that the marginal effect of the policy change on the profit of firm 1 is equal to the marginal effect of policy change on the political contribution. Consequently, we obtain the equilibrium subsidy under the political economy as

$$
s_{P}^{*}(\theta, \mu)=\frac{\left(\theta\left(a\left(1331-1276 \mu+288 \mu^{2}\right)-c\left(1331-1474 \mu+192 \mu^{2}\right)\right)\right.}{(11-4 \mu)(363-165 \mu-2 \theta(121-85 \mu))}
$$

The optimal subsidy becomes positive. Using the subsidy, we derive the optimal contribution. Next, substituting the optimal subsidy into (21) gives the optimal price of the intermediate good, profits of the upstream firm, and the optimal countervailing duty. Substituting the optimal price of the intermediate good and the countervailing duty into (15), (16), (19), and (20) gives the equilibrium quantities and profits of each firm (see Table 1). 
Proposition 2. When political contribution is allowed, as the probability of detecting the subsidy decreases, (a) a self-interested government increases the subsidy, (b) the upstream firm decreases the intermediate good price, (c) The foreign government sets a higher countervailing duty, (d) the aggregate welfare of the exporting country rises while the social welfare of the importing country declines.

The proof is in Appendix A. Proposition 2 shows that even if political contribution is made by the exporting firm, as long as the political weight given to political contribution is not extremely high, the lower subsidy detection probability increases the level of the subsidy as well as the level of the countervailing duty, and decreases the price of the intermediate good. This implies that the lower the intermediate good price, the stronger the competitiveness of the exporting firm in the foreign country, which leads to an increase in the aggregate welfare of the exporting country.

\section{The welfare analysis of the political contribution in the strategic trade policies}

From the comparison of each equilibrium under political contribution and no political contribution, the welfare implications of the case where the political contribution is made by the exporting firm are given as follows.

Lemma 2. The government provides a higher subsidy when it receives the political contribution than when it does not.

The proof is in Appendix A. Lemma 2 says that $s_{P}^{*}(\theta, \mu)$ is always larger than $s_{c}^{*}$ except but $s_{P}^{*}(\theta, \mu)=s_{c}^{*}(\mu)$ at $\theta=1$ in which the government is not interested in receiving political fund at all. The intuition behind this result is provided by (21) that shows that the government pays more attention to the firm 1's profits with a heavier weight on producer surplus with $\theta>1$. Subsequently, the gap between $s_{P}^{*}(\theta, \mu)$ and $s_{c}^{*}$ is monotonically increasing in $\theta$.

Lemma 3. Due to the upstream subsidy, firm 1 can purchase the intermediate good at a reduced price. The price of the intermediate good in the presence of the political contribution is always lower than the intermediate good price without the contribution.

From the optimal intermediate price in (12), it is straightforward to see that $E\left[\mathrm{w}\left(s_{P}^{*}(\theta, \mu), \mu\right]<E\left[\mathrm{w}\left(s_{c}^{*}, \mu\right)\right]\right.$ since $s_{P}^{*}(\theta, \mu)>s_{c}^{*}(\mu)$. A positive price of the intermediate good can be sustained as long as $\theta$ is smaller than $\theta_{1}{ }^{8}$ Otherwise, the intermediate good price becomes negative. A higher $\theta$ promotes a production through a larger subsidy, making the intermediate good price lower. Another interesting result from Lemma 3 is that an intermediate good price with the contribution is lower than that without the contribution. Since firm 1 can purchase intermediate goods at a lower

\footnotetext{
${ }^{8} E\left[\mathrm{w}\left(s_{c}^{*} ; \mu\right)\right] \geq 0$ when $\mu \geq 121(a-5 c) / 78(2 a-c)$ in which, for the positive probability, we assume that $a \geq 5 c$. $E\left[\mathrm{w}\left(s_{P}^{*} ; \mu, \theta\right)\right] \geq 0$ when $\theta \leq \theta_{1}=(33(11 a+33 c-4 a \mu-6 c \mu)) / 4(121 a+121 c-72 a \mu-30 c \mu)$.
} 
price with political contribution, it takes a larger market share and achieves higher profits in international market. On the other hand, firm 2 loses its market share and its profits due to the subsidy practice by the exporting country. Consequently, the subsidy practice makes strategic advantage for the domestic downstream firm (firm 1), making firm 1 more profitable while squeezing the profits of firm 2.

Lemma 4. Comparing the outcomes in the presence of lobbying with ones without lobbying, we obtain: (a) $\Pi_{1}^{*}\left(s_{P}^{*}(\theta, \mu)\right)-C_{P}^{*}>\Pi_{1}^{*}\left(s_{c}^{*}(\mu)\right)$, (b) $\Pi_{2}^{*}\left(s_{P}^{*}(\theta, \mu)\right)<\Pi_{2}^{*}\left(s_{c}^{*}(\mu)\right)$, (c) $\Pi_{u}^{*}\left(s_{P}^{*}(\theta, \mu)\right)>\Pi_{u}^{*}\left(s_{c}^{*}(\mu)\right)$, (d) $s_{P}^{*}(\theta) E\left[q_{1}\left(s_{P}^{*}(\theta, \mu)\right)\right]>s_{c}^{*}(\mu) E\left[q_{1}\left(s_{c}^{*}(\mu)\right)\right]$.

From Lemma 4, the upstream and the downstream firm become more profitable under the regime with political contribution than one without it. The result is that firms in the exporting country might prefer to offer their government a political contribution for upstream subsidy.

Proposition 3. (a) The social welfare, i.e., the general voter's welfare, with the political contribution of exporting firm is always lower than the one without the contribution. (b) As well, the upstream subsidization leads to beggar-thyself when the government is more politically motivated.

Using Lemma 4, we find that the profits for the downstream firm and the upstream firm of the exporting country is higher when political contribution of the firm is allowed than the case without political contribution: $\Pi_{1}^{*}\left(s_{P}^{*}(\theta, \mu)\right)-C_{P}^{*}>\Pi_{1}^{*}\left(s_{c}^{*}(\mu)\right), \Pi_{u}^{*}\left(s_{P}^{*}(\theta, \mu)\right)>$ $\Pi_{u}^{*}\left(s_{c}^{*}(\mu)\right)$. The political contribution makes the subsidy provided by the government of the exporting country excessively high, $s_{P}^{*}(\theta, \mu) q_{1}\left(s_{P}^{*}(\theta, \mu)\right)>s_{c}^{*}(\mu) E\left[q_{1}\left(s_{c}^{*}(\mu)\right)\right]$. Therefore, the social welfare with political contribution is lower than the case without political contribution with the social loss from the excessively high subsidy dominating the corporate gains. This result shows that the politically motivated export subsidy can actually deteriorate social welfare with the upwardly distorted trade policies. In addition, the domestic social welfare decreases when the government is more politically motivated in setting the upstream subsidy. Consequently, the politically motivated government leads to beggaring thyself (Detailed proof in Appendix B).

Proposition 4. The upstream subsidization does not lead to beggar-thy-neighbor when the government is more politically motivated.

Proposition 4 tells us that the upstream subsidization of the exporting country does not result in the welfare deterioration of the foreign country. Proposition 4 can be explained as follows. First, $S W_{2}(\mu)$ is the social welfare of the foreign country when the government of the exporting country is not politically motivated while $S W_{2}(\theta, \mu)$ is the social welfare when the government of the exporting country is politically motivated. In the Appendix $\mathrm{B}$, we show that $S W_{2}(\theta, \mu)$ is always larger than $S W_{2}(\mu)$. Second, the effect of $\theta$ on the social welfare is positive since a positive effect of $\theta$ on consumer surplus and government surplus dominates its negative effect on a 
producer surplus. Thus the social welfare is improved as $\theta$ goes up. Higher $\theta$ results in higher subsidy, which induces the exporting firm to produce more, improving both the consumer surplus and the government surplus in the importing country. The result implies that the importing country might be better off when the government of the exporting country is more politically motivated to subsidize her upstream firms. Thus, remarkably, when the government of the export country is strongly politically motivated, the upstream subsidization in favor of its domestic firm cannot be such a type of trade policy beggaring neighbors.

Proposition 5. The optimal subsidy provided by the exporting country might be dominant to the countervailing duty. When the probability to verify the subsidy is higher, the upward subsidy distortion under political contribution is reduced.

Proof: $s_{P}^{*}(\theta, \mu)-f^{*}(\theta, \mu)>0$ since $\partial s_{P}^{*}(\theta, \mu) / \partial \mu<0, \partial f^{*}(\theta, \mu) / \partial \mu<0$ and

$$
\left\|\partial s_{P}^{*}(\theta, \mu) / \partial \mu\right\|>\left\|\partial f^{*}(\theta, \mu) / \partial \mu\right\| .
$$

Proposition 5 shows that the level of the upstream subsidy is higher than the level of the countervailing duty. In the comparison of export subsidy and countervailing duty, it turns out that the countervailing duty does not fully remedy the distorted price by the exporting subsidy. The intuition behind this result is that the exporting country that provides the upstream subsidy plays as a first mover in the game and extracts "first mover advantage". When it provides the subsidy, it already takes into account the optimal countervailing action by the importing country that plays as a second mover. In this sense, the imposition of the countervailing duty is not strong enough to remedy the distortion caused by the subsidy provided to the upstream firm. A higher detection rate makes the level of the upstream subsidy similar to that of the countervailing subsidy. The difference between subsidy and countervailing duties is larger as detection probability is lower. The amount of subsidy and the countervailing duty is decreased with the probability to verify the subsidy: $\partial s_{P}^{*}(\theta, \mu) / \partial \mu<0, \partial f^{*}(\theta, \mu) / \partial \mu<$ 0 . Since the subsidy is decreased more than the countervailing duty with the probability to detect, $\left\|\partial s_{P}^{*}(\theta, \mu) / \partial \mu\right\|>\left\|\partial f^{*}(\theta, \mu) / \partial \mu\right\|$, the countervailing duty is getting closer to the subsidy level with increasing detection probability. The welfare loss due to the upward distortion of subsidies via political contribution can be reduced by introducing enhanced transparency in the trade policies involved with vertically integrated industrial structures. 


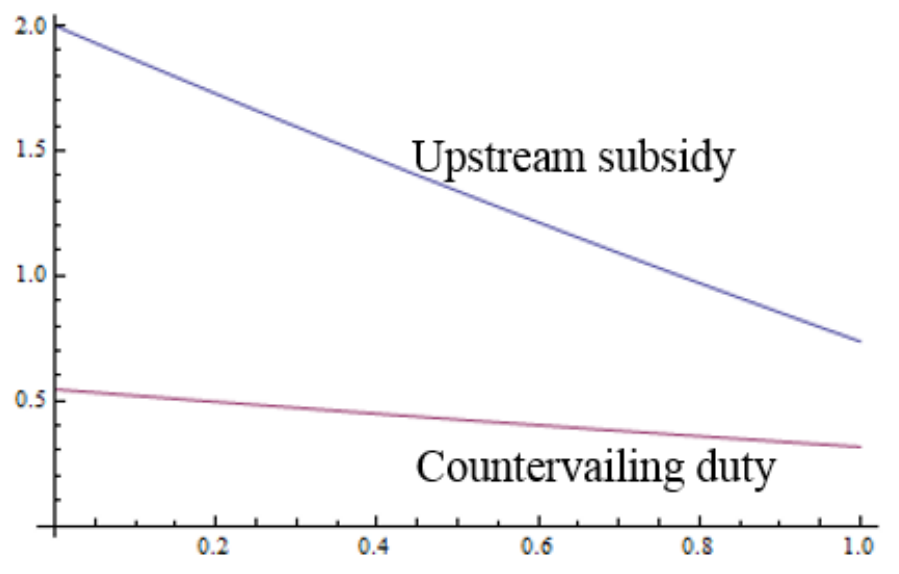

< Figure 1. Upstream subsidy and countervailing duty varying with detection probability >

Proposition 5 also shows that when it is more difficult to detect the upstream subsidy, the exporting country's government has incentives to provide a higher subsidy with the limited effectiveness of countervailing duty, while the difference between the subsidy and the countervailing duty gets lower with the higher probability to verify the upstream subsidy.

\section{Policy implications and concluding remarks}

Considering the latest feature of deepening fragmentation and complicated vertical production networks, this paper examined the welfare impacts of strategic subsidies to upstream firms affected by political contribution of exporting firms with limited verifiability of the subsidy due to the complicated vertical structures. Based on a simple model integrating political contribution provided by exporting firms and verifiability problem of export subsidy to upstream firms within intricately fragmented production process, this paper demonstrates that strategic export policies influenced by political contribution can deteriorate social welfare. Moreover, when it is more difficult to identify the government subsidy to upstream firms within complicated vertical value chains, there is larger distortion due to higher export subsidy influenced by the political contribution. Therefore, even if countervailing duty is imposed against the export subsidy, when the probability to detect the export subsidy is lower, the export subsidy dominates the countervailing duty with the distortion due to political contribution aggravated by the lower detection probability.

The results show that when the verifiability of subsidies provided to upstream firm is low, the optimal subsidy level is much higher than the maximum countervailing duties imposed by importing countries providing higher incentives for abuses of politically manipulated trade policies. Therefore, as it gets more difficult to verify the subsidy provided to upstream production processes, it is more likely that the indirect and hidden strategic government interventions can be made. The results implicate that it is imperative to make coordinated efforts to enhance trade policy transparency 
especially with the involved vertically integrated industrial structures to reduce the welfare distortion caused by the politically manipulated trade policies. The mechanism design for the concrete path to enhance the verifiability would be the task for future studies including institutional arrangement to increase the verifiability of specific government interventions.

\section{Appendix A}

Proof of Proposition 1. Proof is straightforward:

$$
\begin{aligned}
& \frac{\partial s_{c}^{*}(\mu)}{\partial \mu}=-\frac{66\left(154 a(11-4 \mu)^{2}-c\left(22627-9680 \mu+2096 \mu^{2}\right)\right)}{\left(1331-352 \mu-48 \mu^{2}\right)^{2}}<0 \\
& \frac{\partial E\left[\mathrm{w}\left(s_{c}^{*}(\mu)\right)\right]}{\partial \mu}=\frac{363(28 a-23 c)}{2(121+12 \mu)^{2}}>0 \\
& \frac{\partial E\left[f^{*}\left(s_{c}^{*}(\mu)\right)\right]}{\partial \mu}=-\frac{66(28 a-23 c)}{(121+12 \mu)^{2}}<0 .
\end{aligned}
$$

Proof of Proposition 2. Proof is straightforward as below. Unless $\theta$ is extremely high,

$$
\begin{aligned}
& \frac{\partial s_{P}^{*}(\theta, \mu)}{\partial \mu} \\
& =-\frac{66 \theta\left(154 a(11-4 \mu)^{2}+c\left(\theta\left(7986+7744 \mu-5440 \mu^{2}\right)+11\left(-2783+176 \mu+304 \mu^{2}\right)\right)\right)}{(11-4 \mu)^{2}(363-132 \mu-2 \theta(121-72 \mu))^{2}} \\
& <0 \\
& \frac{\partial E[\mathrm{I}(\theta, \mu)]}{\partial \mu}=\frac{363(28 a \theta+c(99-2 \theta(89-28 \theta)))}{2(363-132 \mu-2 \theta(121-72 \mu))^{2}}>0, \\
& \frac{\partial E\left[f^{*}(\theta, \mu)\right]}{\partial \mu}=-\frac{66(28 a \theta+c(99-2 \theta(89-28 \theta)))}{(363-132 \mu-2 \theta(121-72 \mu))^{2}}<0 \\
& \frac{\partial E\left[\mathrm{E}\left[\mathrm{W}\left(s_{P}^{*}(\theta)\right)\right]+(\theta-1) C_{p}(\theta)\right]}{\partial \mu} \\
& =-\frac{(a(11-4 \mu)-2 c(11-\mu))(275 a-187 c+6(2 a-c) \mu)}{2(121+12 \mu)^{2}}<0 .
\end{aligned}
$$

Proof of Lemma 2. Proof is straightforward:

$$
\frac{s_{P}^{*}(\theta, \mu)}{s_{c}^{*}}=\frac{\theta(121+12 \mu)}{363-132 \mu-2 \theta(121-72 \mu)} \geq 1 \text {. }
$$




\section{Proof of Lemma 3.}

By substituting each optimal subsidy into (11) and lemma 1, we obtain the optimal price for the intermediate goods as:

$$
E\left[\mathrm{w}\left(s_{c}^{*}, \mu\right)\right]=\frac{a}{4}+\frac{3 c(11-2 \mu)}{4(11-4 \mu)}-\frac{s_{c}^{*}(\mu)}{2}, \quad E\left[\mathrm{w}\left(s_{P}^{*}(\theta, \mu), \mu\right]=\frac{a}{4}+\frac{3 c(11-2 \mu)}{4(11-4 \mu)}-\frac{s_{P}^{*}(\theta, \mu)}{2}\right.
$$

Proof of Lemma 4. Proof is as follows:

(a) $\Pi_{1}^{*}\left(s_{P}^{*}(\theta, \mu)\right)-C_{P}^{*}$ is increasing in $\theta$ while $\Pi_{1}^{*}\left(s_{c}^{*}\right)$ is unrelated to $\theta$. $\left(\Pi_{1}^{*}\left(s_{P}^{*}(\theta, \mu)\right)-C_{P}^{*}\right) / \Pi_{1}^{*}\left(s_{c}^{*}\right)=1$ if $\theta=1 . \quad$ At $\theta>1, \Pi_{1}^{*}\left(s_{P}^{*}(\theta, \mu)\right)-C_{P}^{*}>$ $\Pi_{1}^{*}\left(s_{c}^{*}(\mu)\right)$ always holds.

(b) $\Pi_{2}^{*}\left(s_{P}^{*}(\theta, \mu)\right)$ is decreasing in $\theta$ while $\Pi_{2}^{*}\left(s_{c}^{*}(\mu)\right)$ is unrelated to $\theta$. $\Pi_{2}^{*}\left(s_{P}^{*}(\theta, \mu)\right) / \Pi_{2}^{*}\left(s_{c}^{*}(\mu)\right)=1$ if $\theta=1 . \quad$ At $\theta>1, \Pi_{2}^{*}\left(s_{P}^{*}(\theta, \mu)\right)<\Pi_{2}^{*}\left(s_{c}^{*}(\mu)\right)$ always holds.

(c) $\Pi_{u}^{*}\left(s_{P}^{*}(\theta, \mu)\right)$ is increasing in $\theta$ while $\Pi_{u}^{*}\left(s_{c}^{*}(\mu)\right)$ is unrelated to $\theta$. $\Pi_{u}^{*}\left(s_{P}^{*}(\theta, \mu)\right) / \Pi_{u}^{*}\left(s_{c}^{*}(\mu)\right)=1$ if $\theta=1 . \quad$ At $\theta>1, \Pi_{u}^{*}\left(s_{P}^{*}(\theta, \mu)\right)>\Pi_{u}^{*}\left(s_{c}^{*}(\mu)\right)$ always holds.

(d) The result is definite since $s_{P}^{*}(\theta, \mu)>s_{c}^{*}(\mu)$ and $E\left[q_{1}\left(s_{P}^{*}(\theta, \mu)\right)\right]>$ $E\left[q_{1}\left(s_{c}^{*}(\mu)\right)\right]$.

\section{Appendix B}

\section{Proof of Proposition 3.}

Proof of part (a): The binding individual rationality of the government is given as: $\mathrm{E}\left[\mathrm{W}\left(s_{P}^{*}(\theta, \mu)\right)\right]+(\theta-1) C_{P}^{*}(\theta, \mu)=\mathrm{E}\left[\mathrm{W}\left(s_{c}^{*}(\mu)\right)\right]$. Therefore, we obtain that $\mathrm{E}\left[\mathrm{W}\left(s_{P}^{*}(\theta, \mu)\right)\right]+(\theta-1) C_{P}^{*}(\theta, \mu)=\mathrm{E}\left[\mathrm{W}\left(s_{c}^{*}(\mu)\right)\right] .<W\left(s_{c}^{*}(\mu)\right)$. More specifically,

$\mathrm{E}\left[\mathrm{W}\left(s_{P}^{*}(\theta, \mu)\right)\right]-C_{P}^{*}(\theta, \mu)<\mathrm{E}\left[\mathrm{W}\left(s_{P}^{*}(\theta, \mu)\right)\right]+(\theta-1) C_{P}^{*}(\theta, \mu)=\mathrm{E}\left[\mathrm{W}\left(s_{c}^{*}(\mu)\right)\right]$

$=\frac{a^{2}(11-4 \mu)^{2}+c^{2}\left(121-124 \mu+4 \mu^{2}\right)-2 a c\left(121-122 \mu+8 \mu^{2}\right)}{968+96 \mu}$

We defined the domestic social welfare in both cases, i.e., the general voter's welfare, are $\mathrm{E}\left[\mathrm{W}\left(s_{P}^{*}(\theta, \mu)\right)\right]-C_{P}^{*}=\Pi_{1}^{*}\left(s_{P}^{*}(\theta, \mu)\right)-C_{P}^{*}+\Pi_{u}^{*}\left(s_{P}^{*}(\theta, \mu)\right)-s_{P}^{*}(\theta, \mu) q_{1}\left(s_{P}^{*}(\theta, \mu)\right)$, $\mathrm{E}\left[\mathrm{W}\left(s_{c}^{*}(\mu)\right)\right]=\Pi_{1}^{*}\left(s_{c}^{*}(\mu)\right)+\Pi_{u}^{*}\left(s_{c}^{*}(\mu)\right)-s_{c}^{*}(\mu) q_{1}\left(s_{c}^{*}(\mu)\right) \quad$. $\quad$ Then subtracting $\mathrm{E}\left[\mathrm{W}\left(s_{P}^{*}(\theta, \mu)\right)\right]-C_{P}^{*}(\theta, \mu)$ in which there is the political contribution from $\mathrm{W}\left(s_{c}^{*}(\mu)\right)$ in 
which there is not any contribution gives

$$
\begin{aligned}
& \mathrm{E}\left[\mathrm{W}\left(s_{P}^{*}(\theta, \mu)\right)\right]-C_{P}^{*}(\theta, \mu)-E\left[\mathrm{~W}\left(s_{c}^{*}(\mu)\right)\right] \\
& =\underbrace{\Pi_{1}^{*}\left(s_{P}^{*}(\theta, \mu)\right)-C_{P}^{*}(\theta, \mu)-\Pi_{1}^{*}\left(s_{c}^{*}(\mu)\right)}_{+}+\underbrace{\Pi_{u}^{*}\left(s_{P}^{*}(\theta, \mu)\right)-\Pi_{u}^{*}\left(s_{c}^{*}(\mu)\right)}_{+} \\
& -\underbrace{s_{P}^{*}(\theta, \mu) q_{1}\left(s_{P}^{*}(\theta, \mu)\right)-s_{c}^{*}(\mu) q_{1}\left(s_{c}^{*}(\mu)\right)}_{+}<0 .
\end{aligned}
$$

Proof of part (b): First we define the aggregate welfare of the exporting country $\mathrm{E}\left[\mathrm{W}\left(s_{P}^{*}(\theta, \mu)\right)\right]+(\theta-1) C_{P}^{*}(\theta, \mu)$

Then, with (24), taking first derivative of the domestic social welfare with respect to $\theta$ must be zero as follows:

$$
\frac{\partial \mathrm{E}\left[\mathrm{W}\left(s_{P}^{*}(\theta, \mu)\right)\right]}{\partial \theta}+C_{P}^{*}(\theta, \mu)+(\theta-1) \frac{\partial C_{P}^{*}(\theta, \mu)}{\partial \theta}=0
$$

Since $C_{P}^{*}(\theta, \mu)$ is increasing in $\theta$, we have

$$
\frac{\partial \mathrm{E}\left[\mathrm{W}\left(s_{P}^{*}(\theta, \mu)\right)\right]}{\partial \theta}-\frac{\partial C_{P}^{*}(\theta, \mu)}{\partial \theta}=-C_{P}^{*}(\theta, \mu)-\theta \frac{\partial C_{P}^{*}(\theta, \mu)}{\partial \theta}<0
$$

Thus, $\mathrm{E}\left[\mathrm{W}\left(s_{P}^{*}(\theta, \mu)\right)\right]-C_{P}^{*}$ is decreasing in $\theta$.

\section{Proof of Proposition 4.}

First, we define the social welfare of the foreign country as

$$
\begin{gathered}
S W_{2}(\mu)=\underbrace{U\left(E[\mathrm{w}(\mu)], f^{*}(\mu)\right)}_{C S}+\underbrace{\pi_{2 V}\left(E[\mathrm{w}(\mu)], f^{*}(\mu)\right)}_{P S}+\underbrace{f^{*}(\mu) q_{1 V}\left(E[\mathrm{w}(\mu)], f^{*}(\mu)\right)}_{G S} \\
S W_{2}(\theta, \mu)=\underbrace{\pi_{2 V}\left(E[\mathrm{w}(\theta, \mu)], f^{*}(\theta, \mu)\right)}_{+\underbrace{U\left(E[\mathrm{w}(\theta, \mu)], f^{*}(\theta, \mu)\right)}_{C S}+\underbrace{f^{*}(\theta, \mu) q_{1 V}\left(E[\mathrm{w}(\theta, \mu)], f^{*}(\theta, \mu)\right)}_{\text {S }}}
\end{gathered}
$$

1) $S W_{2}(\theta, \mu)-S W_{2}(\mu)=-\frac{c^{2}(\theta-1)\left(2662-2453 \mu+624 \mu^{2}\right)(A+\theta B)}{2(121+12 \mu)^{2}(363-132 \mu-2 \theta(121-72 \mu))^{2}}>0$

where $(A+\theta B)<0$ since $\theta>1, \quad A=-2371842 \mu+541156 \mu^{2}+156952 \mu^{3}-$ $9024 \mu^{4}<0$, and $B=-322102+1723645 \mu-730774 \mu^{2}-152272 \mu^{3}+10752 \mu^{4}<0$. We assume that $a=5 c$ and $b=1$. 
We graphically show that $B$ takes a negative value with the parameter ranges, $\theta \in$ $[1,2]$ and $\mu \in[0,1]$.

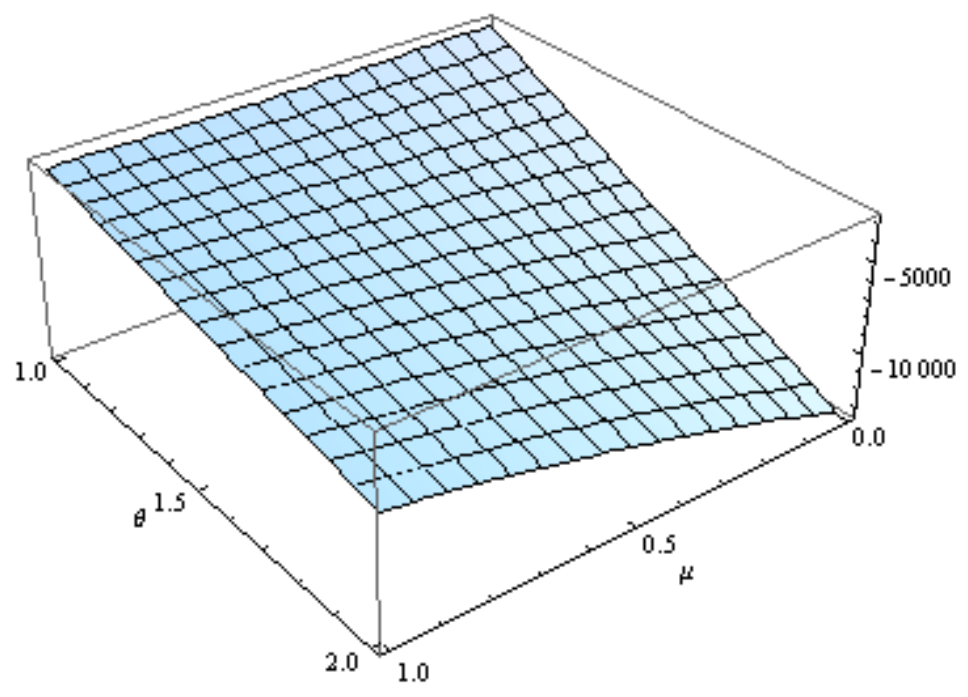

2) $\frac{S W_{2}(\mu)}{\partial \theta}=\underbrace{\frac{\partial U\left(E[\mathrm{w}(\theta, \mu)], f^{*}(\theta, \mu)\right)}{\partial \theta}}_{(+)}+\underbrace{\frac{\partial \pi_{2 V}\left(E[\mathrm{w}(\theta, \mu)], f^{*}(\theta, \mu)\right)}{\partial \theta}}_{(-)}$

$+\underbrace{\frac{\partial f^{*}(\theta, \mu) q_{1 V}\left(E[\mathrm{w}(\theta, \mu)], f^{*}(\theta, \mu)\right)}{\partial \theta}}_{(+)}=-\frac{\left(2662-2453 \mu+624 \mu^{2}\right) C}{2(363-132 \mu+2 \theta(-121+72 \mu))^{3}}>0$

where $C=7986-10373 \mu+3336 \mu^{2}+80 \mu^{3}-8 \theta\left(1331-1199 \mu+366 \mu^{2}-8 \mu^{3}\right)<0$. We assume that $a=5 c$ and $b=1$.

Graphically, we show that part $C$ is negative, with the parameter ranges, $\theta \in[1,2]$ and $\mu \in[0,1]$.

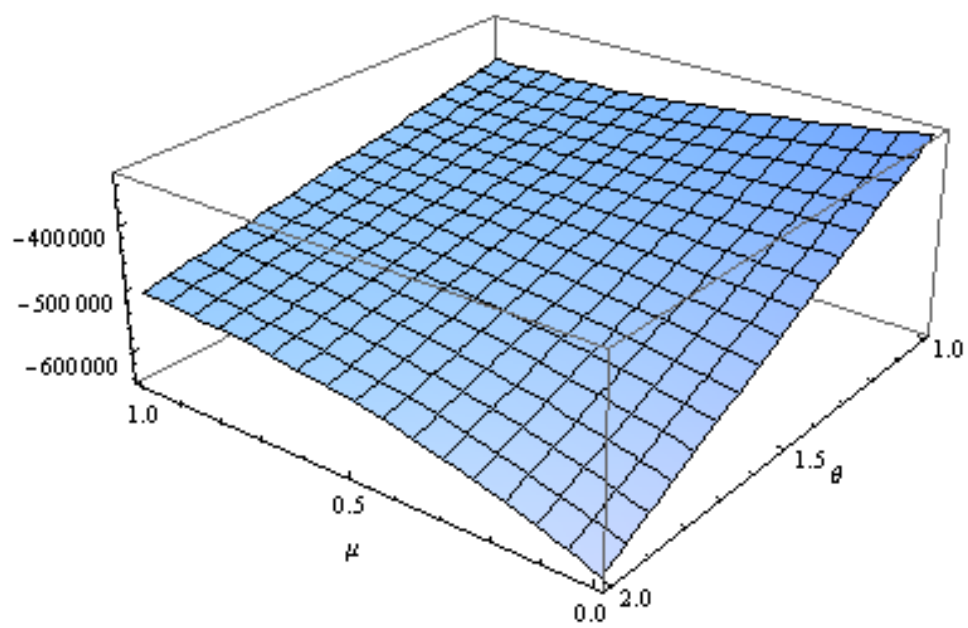




\section{$<$ The equilibrium parameter values of equilibrium with and without political contribution >}

\begin{tabular}{|c|c|}
\hline Equilibrium with political contribution & Equilibrium without political contribution \\
\hline $\begin{array}{l}s_{p}^{*}(\theta, \mu) \\
=\frac{\theta\left(a\left(1331-1276 \mu+288 \mu^{2}\right)-c\left(1331-1474 \mu+192 \mu^{2}\right)\right)}{(11-4 \mu)(363-132 \mu-2 \theta(121-72 \mu))}\end{array}$ & $\begin{array}{l}s_{c}^{*}(\mu) \\
=\frac{a\left(1331-1276 \mu+288 \mu^{2}\right)-c\left(1331-1474 \mu+192 \mu^{2}\right)}{(11-4 \mu)(121+12 \mu)}\end{array}$ \\
\hline $\begin{array}{l}C_{p}^{*}(\theta, \mu) \\
=\frac{(\theta-1)(a(11-4 \mu)(121-72 \mu)-c(1331-2(737-96 \mu) \mu))^{2}}{2(121+12 \mu)(363-132 \mu-2 \theta(121-72 \mu))^{2}}\end{array}$ & \\
\hline $\begin{array}{l}E[I(\theta, \mu)] \\
=\frac{c(99(11-2 \mu)+4 \theta(-121+30 \mu))+a(363-132 \mu-4 \theta(121-72 \mu))}{4(363-132 \mu-2 \theta(121-72 \mu))}\end{array}$ & $E[I(\mu)]=\frac{a(156 \mu-121)+c(605-78 \mu)}{4(121+12 \mu)}$ \\
\hline$E\left[f^{*}(\theta, \mu)\right]=\frac{3(a(11-4 \mu)-2 c(22-5 \mu-\theta(11-4 \mu)))}{363-132 \mu-2 \theta(121-72 \mu)}$ & $E\left[f^{*}(\mu)\right]=\frac{a(33-12 \mu)-6 c(11-\mu)}{121+12 \mu}$ \\
\hline$q_{1 V}(\theta, \mu)=\frac{7 a(11-4 \mu)+c(55-62 \mu-88 \theta(1-\mu))}{2(363-132 \mu-2 \theta(121-72 \mu))}$ & $q_{1 V}(\mu)=\frac{7 a(11-4 \mu)-c(33-26 \mu)}{2(121+12 \mu)}$ \\
\hline$q_{1 N}(\theta, \mu)=\frac{11 a(11-4 \mu)-c(121-(56 \theta-22) \mu)}{2(363-132 \mu-2 \theta(121-72 \mu))}$ & $q_{1 N}(\mu)=\frac{11 a(11-4 \mu)-c(121-34 \mu)}{2(121+12 \mu)}$ \\
\hline $\begin{array}{l}q_{2 v}(\theta, \mu) \\
=\frac{a(649-236 \mu-4 \theta(121-72 \mu))-c(781-326 \mu-\theta(572-376 \mu))}{4(363-132 \mu-2 \theta(121-72 \mu))}\end{array}$ & $q_{2 v}(\mu)=\frac{a(165+52 \mu)-c(209+50 \mu)}{4(121+12 \mu)}$ \\
\hline $\begin{array}{l}q_{2 N}(\theta, \mu) \\
=\frac{a(605-220 \mu-4 \theta(121-72 \mu))-c(605-286 \mu-4 \theta(121-86 \mu))}{4(363-132 \mu-2 \theta(121-72 \mu))}\end{array}$ & $q_{2 N}(\mu)=\frac{a(121+68 \mu)-c(121+58 \mu)}{4(121+12 \mu)}$ \\
\hline
\end{tabular}

\section{References}

Bagwell, Kyle and Robert W. Staiger. 2006. "Will International Rules on Subsidies Disrupt the World Trading System?" The American Economic Review, 96(3): 877-895.

Brander, James A. and Barbara J. Spencer. 1985. "Export Subsidies and International Market Share Rivalry" Journal of International Economics, 18(1): 83-100.

Bull, Jesse and Joel Watson. 2004. "Evidence Disclosure and Verifiability" Journal of Economic Theory, 118(1): 1-31.

Collie, David. 1991. "Export Subsidies and Countervailing Tariffs" Journal of International Economics, 31(3-4): 309-324.

Dixit, Avinash. 1988. "Anti-Dumping and Countervailing Duties Under Oligopoly" European Economic Review, 32(1): 55-68.

Eaton, Jonathan and Gene M. Grossman. 1986. "Optimal Trade and Industrial Policy Under Oligopoly" The Quarterly Journal of Economics, 101(2): 383-406. 
Fung, K. C., Chelsea C. Lin, and Ray-Yun Chang. 2009. "The Political Economy of Strategic Trade Policies*" Review of International Economics, 17(3): 494-509.

Gaudin, Germain. 2016. "Pass-through, Vertical Contracts, and Bargains" Economics Letters, 139: 14.

Goh, Ai-Ting. 2005. "Knowledge Diffusion, Input Supplier's Technological Effort and Technology Transfer Via Vertical Relationships" Journal of International Economics, 66(2): 527-540.

Grossman, Gene M. and Elhanan Helpman. 1994. "Protection for Sale" The American Economic Review, 84(4): 833-850.

Horlick, G. and PA Clarke. 2016. "Rethinking Subsidy Disciplines for the Future" E15 Initiative, Synthesis of the Policy Options(18).

Ishikawa, Jota and Yoshimasa Komoriya. 2007. "Subsidies and Countervailing Duties with Firm Heterogeneity" Asia-Pacific Journal of Accounting \& Economics, 14(3): 279-291.

Kagitani, Koichi. 2009. "Political Economy of Strategic Export Policy in a Differentiated Duopoly*" Japanese Economic Review, 60(2): 236-252.

Kayalica, M. Ö. and Sajal Lahiri. 2007. "Domestic Lobbying and Foreign Direct Investment. the Role of Policy Instruments" The Journal of International Trade \& Economic Development, 16(3): 299323.

Kvaløy, Ola and Trond E. Olsen. 2009. "Endogenous Verifiability and Relational Contracting" The American Economic Review, 99(5): 2193-2208.

Lee, Gea M. 2016. "Optimal International Agreement and Restriction on Domestic Efficiency" Journal of International Economics, 99: 138-155.

-----. 2016. "Subsidies and Countervailing Duties" Handbook of Commercial Policy, 1: 161-210.

Lin, Ping and Kamal Saggi. 2007. "Multinational Firms, Exclusivity, and Backward Linkages" Journal of International Economics, 71(1): 206-220.

OECD, Policy R. Competition, State Aids and Subsidies, 2010.

Spencer, Barbara J. 1988. "Capital Subsidies and Countervailing Duties in Oligopolistic Industries" Journal of International Economics, 25(1-2): 45-69.

Sykes, Alan O. 2005. "Subsidies and Countervailing Measures." In The World Trade Organization: Legal, Economic and Political AnalysisAnonymous , 1682-1706: Springer. 